\title{
SILUETAS DE LA CIUDAD HERIDA
}

\author{
PRIMERA SILUETA
}

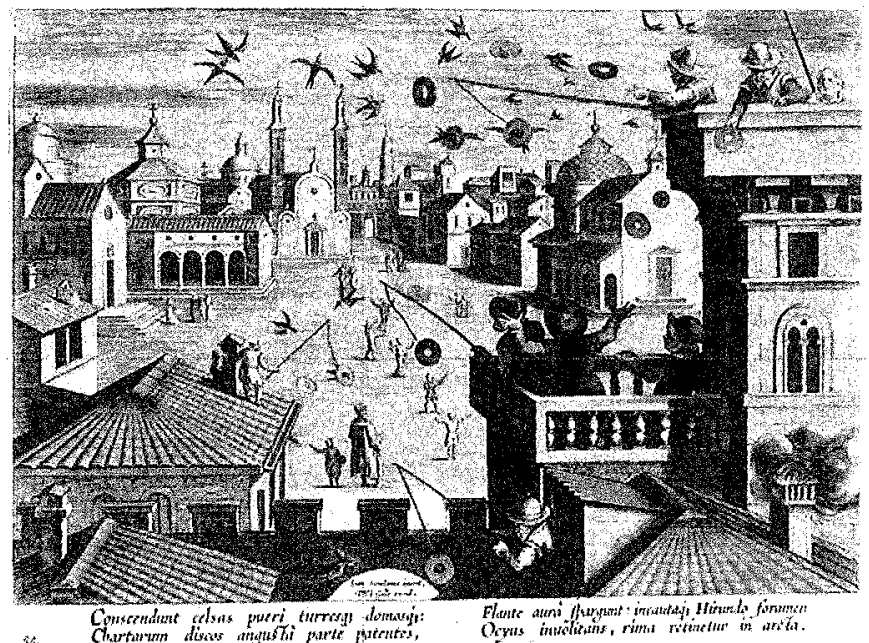

La ciudad recoge siempre la función fundadora de la diferencia, discernir en palabras de $R$. Barthes: la ciudad es una enumeración de autoconstrucción de los mitos, que la persona necesita para sobrevivir entre la tensión y el deseo de la vida; por eso los espacios de la ciudad configuran entornos de sabiduría que se completan con el acontecer de sus tiempos poéticos. 


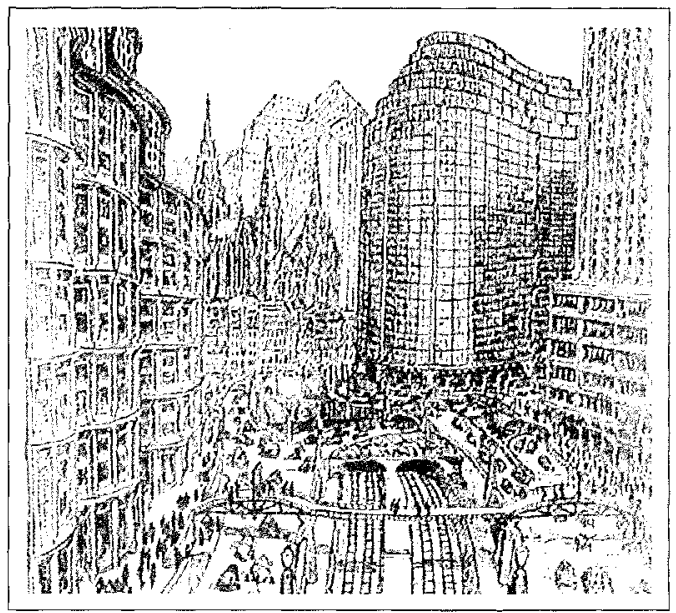

SEGUNDA SILUETA

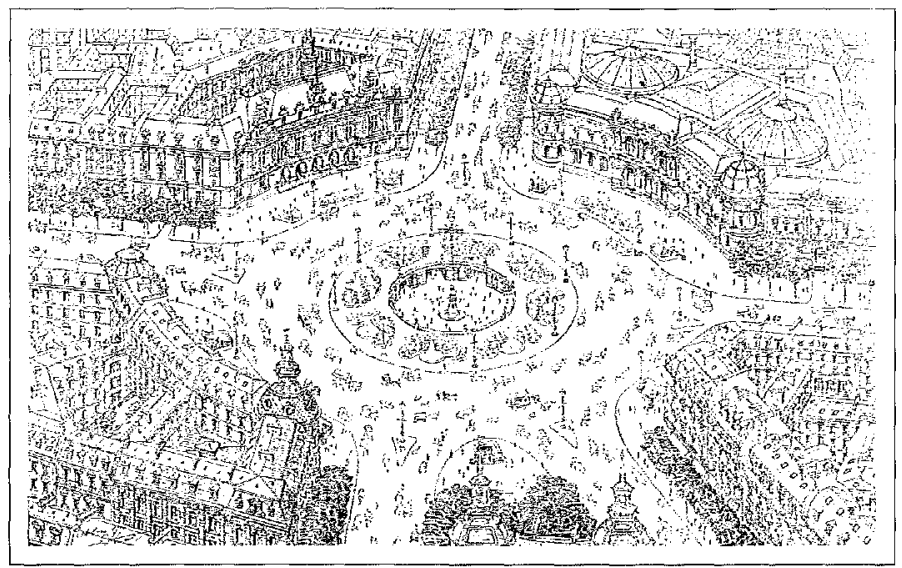

Líneas, perfiles, geometrías del tiempo. La ciudad, como muestran las huellas de los hombres se encuentra en arquitecturas abandonadas. La ruina como condición biológica nutrida tal vez por los vientos o renovada por la monotonía de las miradas silenciosas que transforman la materia en metáfora plástica. La inteligencia mercantil todo lo mineraliza y no permite acortar la distancia que hay entre el valle y la acrópolis, el ágora y el parque temático, entre el consumir y el contemplar (Alby, Santiago de Compostela, Chartres, Lisboa...). 


\section{TERCERA SILUETA}

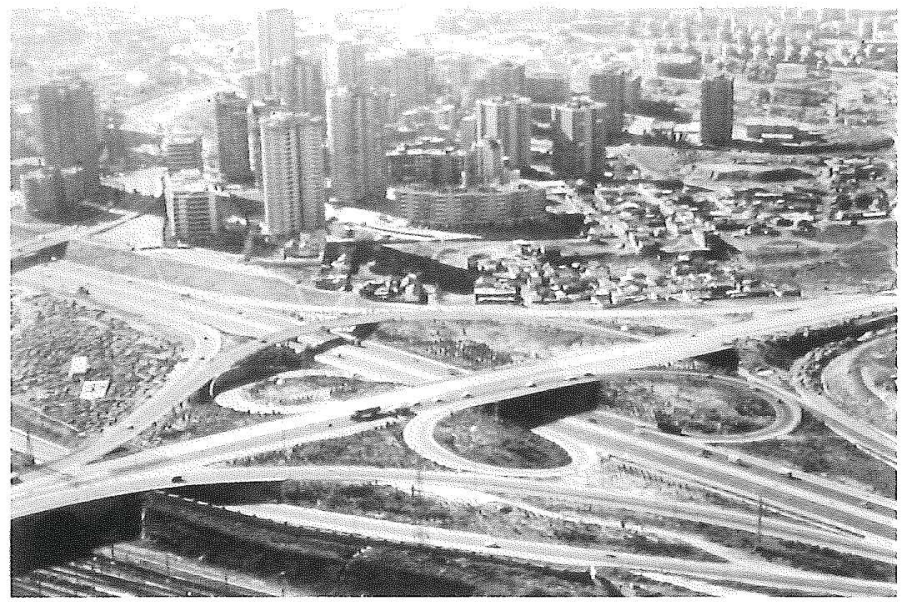

La ciudad moderna nos enseña que no son aceptables taxonomías tan radicales que anulan los espacios de la historia; huérfanos de tan aleatoria jactancia, la rigurosa cultura urbana entiende la ciudad hoy como una cualidad temporal ligada al triangulo metálico de la economía global: producción, intercambio y consumo, terna vitrubiana que desencadenan las nuevas relaciones con los habitantes metropolitanos; trabando cuerpo y alma con los objetos que producen y le rodean, adorada energía informada de caducidad concreta, aunque sus imágenes sean tan codiciadas como una «mariposa en cenizas desatada» (Góngora), (Barcelona, Bilbao, Madrid, Valencia...). 


\section{CUARTA SILUETA}

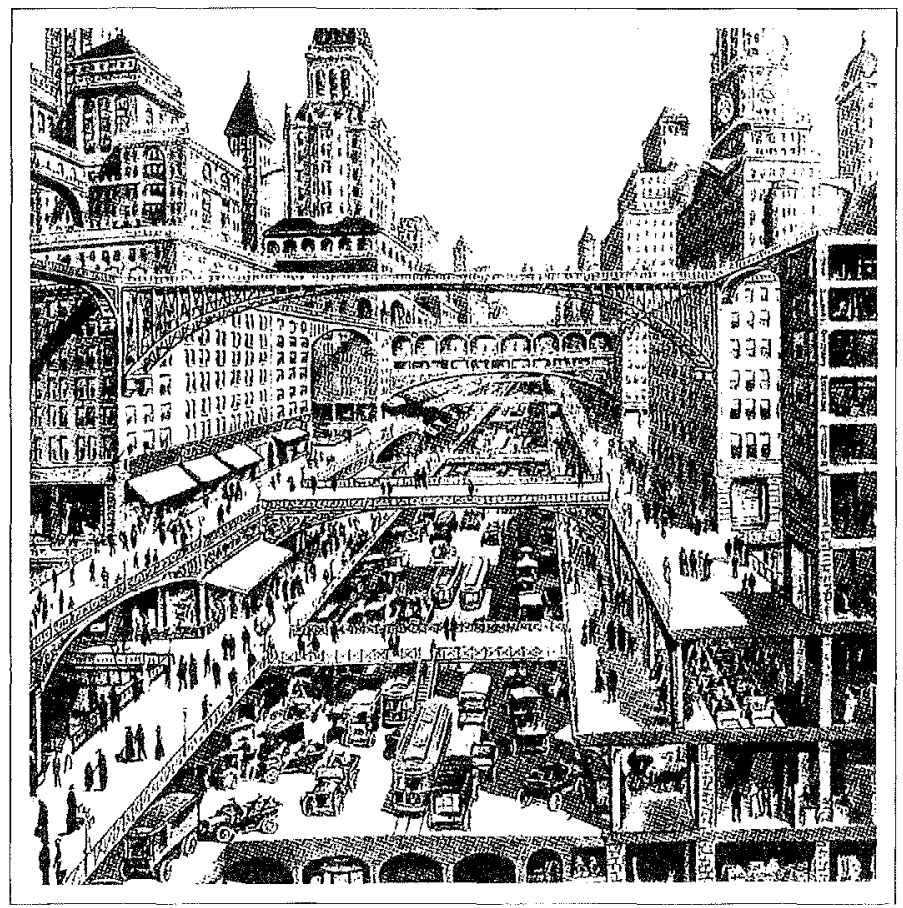

A veces la ciudad se nos representa como los vestigios de un gran «opus», máquina de fábricas, selva de celebridades, algunas desechables. Monumentales obras que se edificaron esperando alcanzar «memoria de la voluble fortuna», en un intento más de la inmisericorde lucha contra su disolución en el tiempo, y poder así defenderse del reducto final del olvido (El Escorial, La Alhambra, Sevilla, Salamanca...). 


\section{QUTNTA SILUETA}

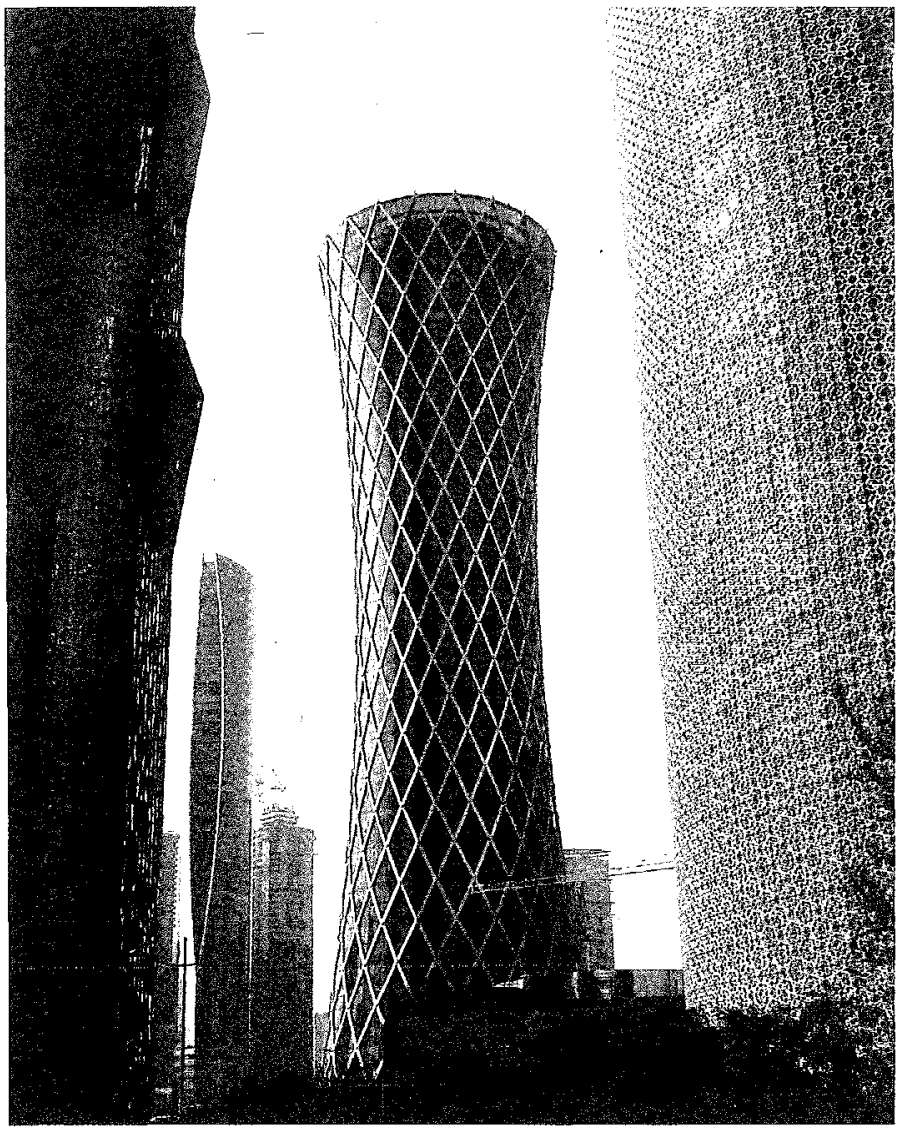

Si la función, como axioma no pautado de la modernidad, es el destino que habita en la morada de la forma, tendremos que admitir que en la nueva condición metropolitana existe un lenguaje para los espacios de la función y otro lenguaje para los lugares de la forma edificada; tan dislocada semántica impone a nuestras informatizadas colectividades sobrevivir en un archipiélago de solitarios espacios republicanos carentes de imaginación cívica, añorando, tal vez, la pureza de aquel ilusionado ensueño de la razón instrumental que consiguió que la ciudad se transformara en un dislocado «orden tecnológico» (México, Nueva York, Pekín, Tolrio, São Paulo...). 


\section{SEXTA SILUETA}

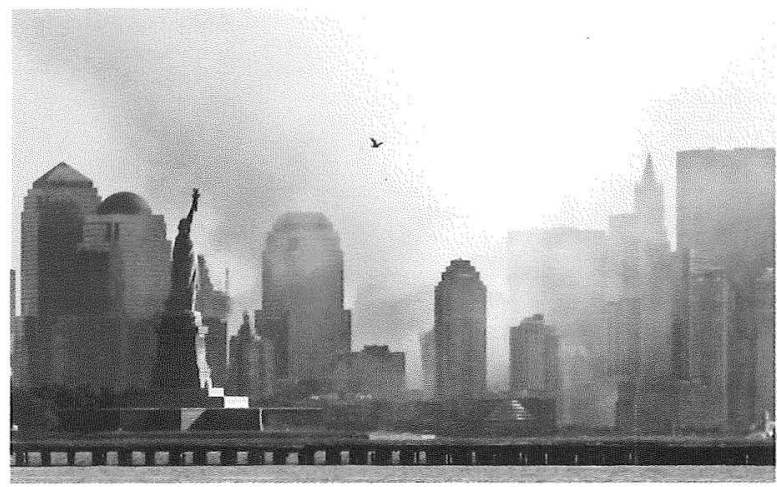

La nueva metrópoli no debe renunciar a ser solo el «condensador simbólico» de las sociedades que por sus recintos deambulan. La arquitectura en desmesura y sin límites, a veces, corona la "gloria» y se comporta como profecía inmoral de republicana convivencia. Después de Babel, nos alerta Flaubert: «No conviene tocar los ídolos; su corteza dorada podría quedarse entre las manos». Pensar la nueva metrópoli requiere recuperar la meditación de aquel constructor fugitivo por la naturaleza, que miraba con la sensibilidad del poeta, medía con la equidad del agrimensor y edificaba según los reflejos que le proporcionaba la materia, precavido que tal armonía no debía desaparecer porque su destrucción como su ruina se transformaba en doloroso escándalo inhumano ( $\mathrm{Na}$ gasaki, Berlín, San Petersburgo, Sarajevo, Alepo...).

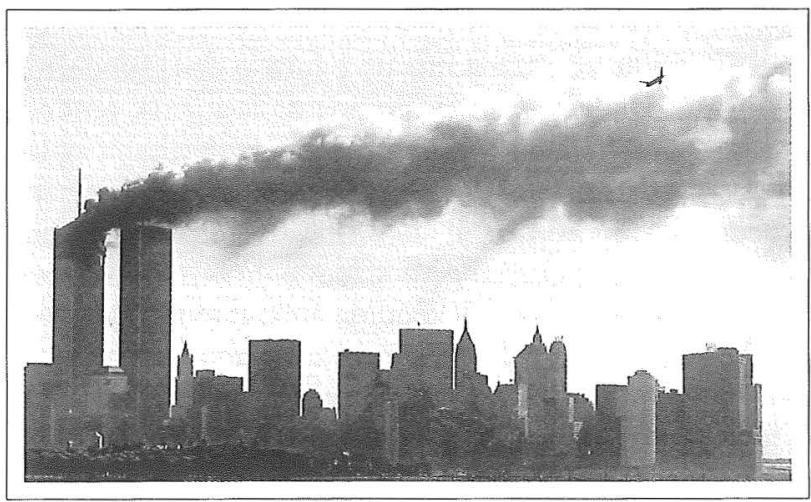




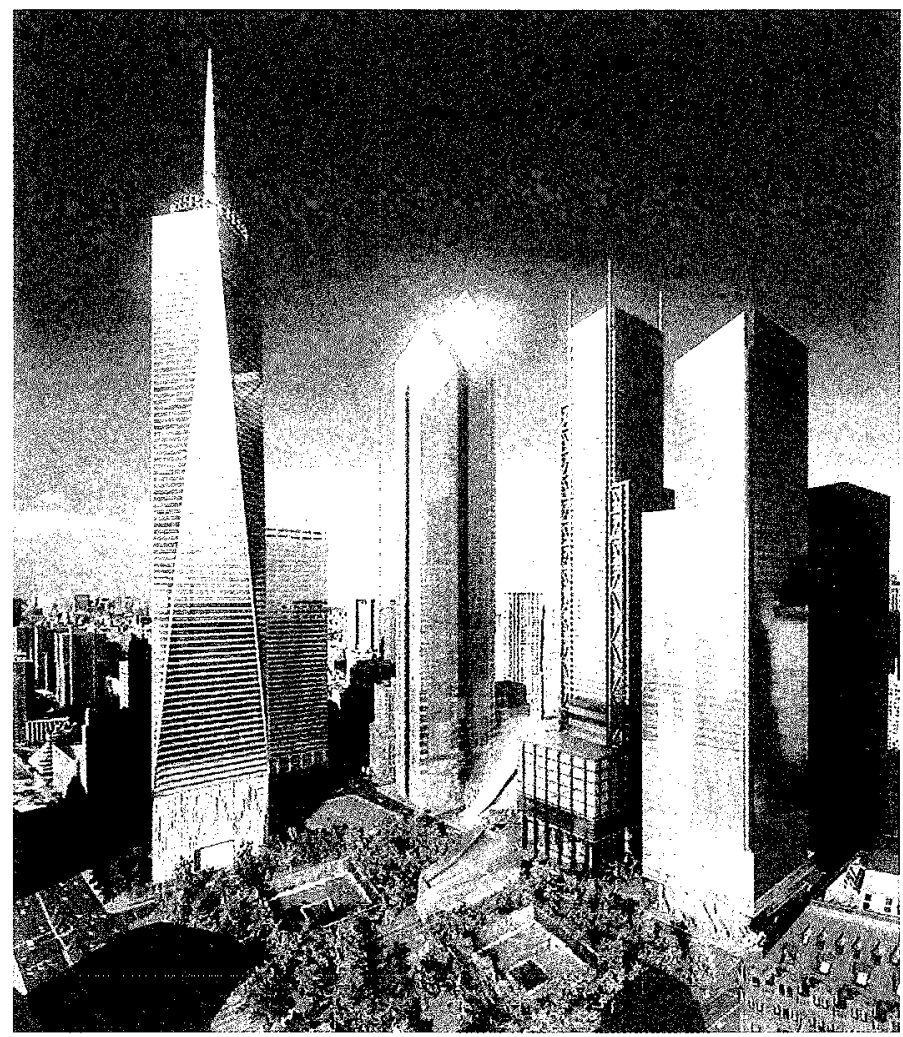

El rascacielos, opus sublime, lábil fortaleza que alberga los límites de una cultura acotada, entre la angustia solidaria y la injusticia renovada, metáfora del tiempo del menhir burocrático contra el dolmen arcaico del suburbio de nuestras conflictivas metrópolis; signos inequívocos de la utopía construida de la civilización tecnológica, también visión de la ciudad como infierno secularizado.

Su ruina, tal vez, la contemplamos como los signos de la pureza de un sueño, como un calidoscopio sin reflejos, como solar de una patria del desarraigo, donde el tiempo se trasmutó en presente desasosiego y la ciudad asumió la profecía de sumisión (Nueva York, Chicago, Dubái, Shanghái...). 


\section{OCTAVA SILUETA}

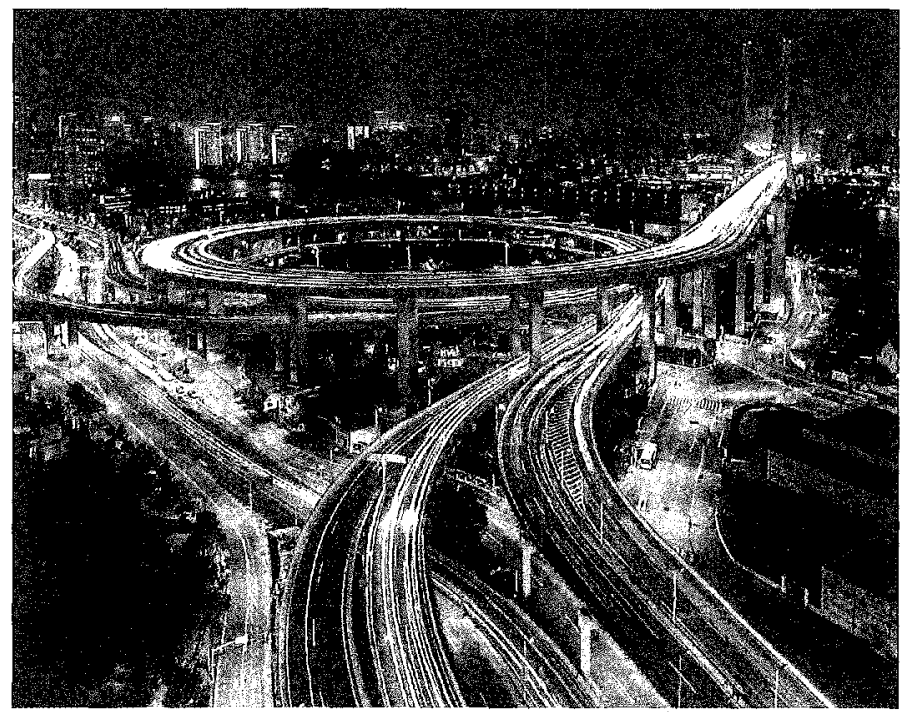

En la región de lo no construido, alrededor de la ciudad edificada, existía un espacio limítrofe, habitado por seres de naturaleza ambigua que caracterizaba lo humano y animal; más allá se entrelazaba la madre naturaleza donde habitaban los genios del bien y del mal; eran los lugares inciertos o territorios de lo sublime. Hoy colonizados por los poderes incontrolados de la tecnología, donde se asienta un sistema de servicios que conmociona las relaciones entre percepción psicológica y realidad física en las ilimitadas geografías de lo sublime digital. 


\section{NOVENA SILUETA}

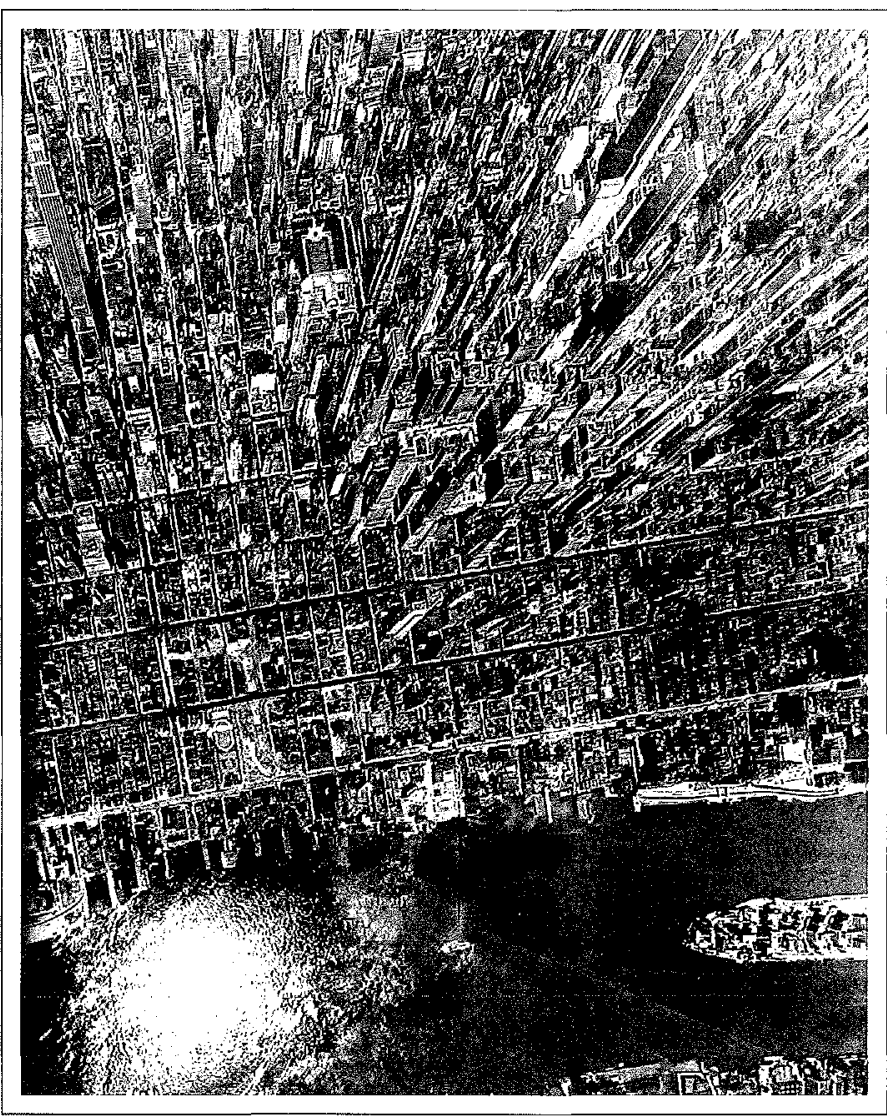

La calle en la ciudad tradicionalmente se entendía como espacio de una arquitectura que ordenaba la heterogénea vida de lo urbano; movilidad y ordenación espacial integraban usos residenciales, productivos, de ocio y circulación.

La calle se transformó en carretera de ciudad en el amanecer de la metrópoli y la metrópoli no puede sobrevivir sin una geometría de traza acorde entre movilidad, ordenación espacial de la ciudad, territorio, medio urbano y rural; proyecto integral de la ordenación espacial de la movilidad, paisaje innovador que necesita el diseño funcional, técnico y emocional para edificar los nuevos lugares de la metrópoli. 


\section{DÉCIMA SILUETA}

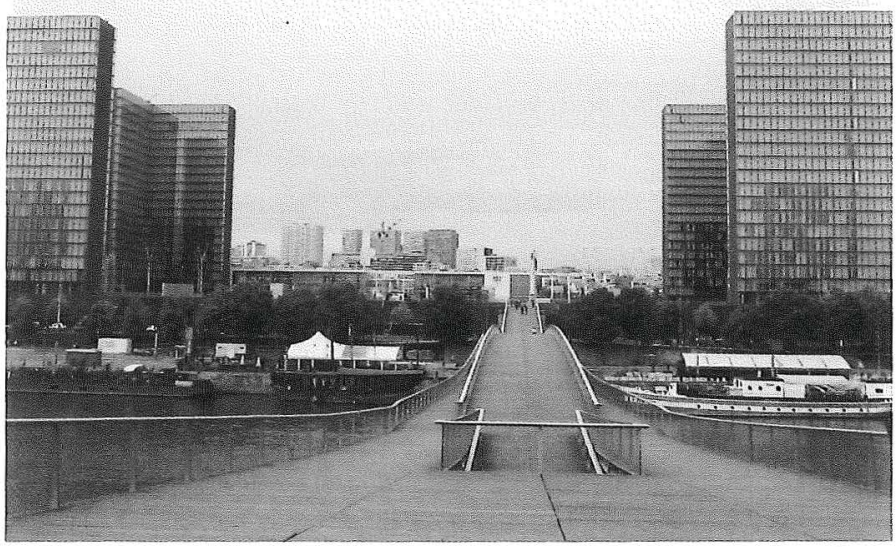

Las pequeñas comunidades de la ciudad burguesa mantenían vigentes las relaciones humanas, junto a la fractura que se manifestaba en forma de alineación y segregación social en las anónimas concentraciones metropolitanas.

Los ecos finales de aquella profecía de progreso promovían y alentaban la voluntad de la acción para que tal relato se cumpliera; ante la miseria que rondaba lo inseguro de sus respuestas, para tal cometido se intentaba formular el locus civitatis desde la acción del método científico como integración positiva entre naturaleza y cultura y la aguda presión de la crítica social.

En la deriva de tales opciones para la construcción del lugar de la ciudad, dos aptitudes predominan hoy, elocuentes en el proyecto del lugar: aquellos que provienen del desarrollo científico-técnico y las vanguardias del evolucionado mundo digital. Su configuración morfológica en lugares de la ciudad están sitiados por las inestables políticas urbanas de la economía capitalista de mercado; su arquitectura y doctrina dejan huella elocuente en la ciudad herida y la agresión metropolitana del medio ambiente. 
La arquitectura, pese a todos sus apartados de contingencias y necesidades, reside en la forma. Se trata de una cuestión predominantemente de índole artística, aunque sufra las derivaciones que infieren las acciones políticas, las relaciones económicas y los hallazgos tecnológicos. El espacio de la arquitectura es forma en el tiempo.

Destronar a la arquitectura de su dimensión utópica es como amputar al poeta su capacidad de poder construir con metáforas. El proyecto de la arquitectura es pura especulación utópica; intuir el no lugar y describirlo sin prescindir del recorrido por el enigma que encierra la memoria. La arquitectura como paisaje de acontecimientos abiertos a desvelar el enigma en la imagen utópica.

La utopía artística de la modernidad tuvo desde sus orígenes una tutela activa por parte de la economía capitalista y pronto se integró en las demandas de la producción industrial; esta integración tenía unos valores de innovación y de cambio esperanzador: el nuevo paisaje del humanismo social de la época y la conquista progresiva de la difícil democracia proyectual.

Edificar la arquitectura sin materia y sin sentido de la forma, esa abstracción que denominamos espacio, puede aspirar solo a ser depositaria de una orfandad imaginaria donde apenas florecen los lugares de la arquitectura.

El espacio entendido solo desde la forma es ignorar la capacidad simbólica de la arquitectura como lugar de significados y reflejo de acontecimientos funcionales. La forma en arquitectura siempre pretendió ser «comarca de libertad», donde se expresa el lenguaje de la arquitectura, también en libertad.

Los operadores del diseño y proyecto de la arquitectura en la sociedad de consumo globalizado se han transformado en un ejercicio que administra la construcción tecnológica del espacio, ordena el control publicitario de los símbolos y gestiona la producción académica de la forma en las diversas arquitecturas que pueblan los espacios de la ciudad.

La crítica de la cultura arquitectónica está sometida, como en otros campos, a la dialéctica del plusvalor, de manera que esta dualidad «arquitectura de masas»-«arquitectura de élite» es la 
esencia de alguno de los operadores del diseño consagrado; se solicita en sus proyectos cómo simular con brillantes imágenes virtuales los recintos donde ritualizar las ceremonias del intercambio y el trueque. Basta con observar la imagen del último hipermercado de la arquitectura.

Los conflictos que existen entre riqueza oligárquica y riqueza democrática que actúan en las sociedades contemporáneas, términos que Roy Harrod había sugerido como causa significativa de la ruptura del orden biológico-social, ponen en evidencia que el acontecer biológico-social de la metrópoli moderna provoca una cadena de nuevas estructuras bastante diferentes de los procesos primarios en los cuales fue concebido, este lugar de convivencia que denominamos ciudad.

La idea de una ciudad, concebida como conjunto de sistemas abiertos, de naturaleza diversificada que haga posible la coherencia de tensiones entre un todo casi integrado (redes de energía, comunicaciones, nuevas tecnologías) y unas partes diferenciadas, recintos para el nuevo hábitat civilizatorio superadores de otros modelos restrictivos, de ordenanzas y leyes proteccionistas para aquellos que son los que poseen la tierra y se oponen a instaurar el equilibrio de la razón a nuestro hábitat.

En una situación como la que hoy contempla el horizonte del arquitecto, sin una ética que regule el proyecto moral de su actividad profesional y una crítica que aclare la demanda de postulados artísticos que se solicita del proyecto, la arquitectura del último arquitecto está entretenida en asumir la servidumbre del sistema, a cambio de la fruición que le produce la representación de lenguajes que desconoce, con la idea de que vivimos en un tiempo de inmaterialidad cristalina y que habitamos, con seducción e ironía, «las torres de las mil lenguas» en el imperio de la razón abatida.

Academias y escuelas de arquitectura continúan prefabricando ídolos de madera. Hölderlin con poética precisión lo había descrito: «Ídolos de madera a los que nada falta porque sus almas son tan pobres que no preguntan por la lluvia y el brillo del sol porque no tienen nada que requiera cuidado». La historia del hombre es la historia de sus realizaciones, que se aproximan más al noble ejercicio del poeta, y que su trabajo puede discurrir por los territorios de lo imaginario sin peligro que una cierta evasión de la materia se desvanezca en formas innecesarias. 
Baudelaire dejó bien acuñada aquella exclamación profética en torno a la ciudad: « $\mathrm{O}$ b materia vivientel, ya no eres más que un bloque de granito rodeado de un vago espanto».

Vivimos en la actualidad una difusa idealización telemática sobre el futuro de las metrópolis, mientras soportamos el viejo idealismo protoindustrial de una teoría de lo auténticamente falso, el mismo idealismo que durante el siglo precedente nos ilustró con catástrofes como las que provocaron los hornos crematorios o la bomba atómica, y seguimos afirmando que las nuevas tecnologías configuraran unos recintos más apacibles acondicionados por las autopistas de la información en una cadena de preguntas y respuestas sin fin.

Tramas autorreguladas nos pondrán a prueba los precarios límites de la libertad y de la democracia; la sincronización del tiempo pasado y del futuro en el tiempo presente es una fractura, sin duda dolorosa, entre memoria y utopía, de manera que el espacio de nuestros ámbitos urbanos habrá sufrido la amputación de los tiempos de la razón, y quién sabe si estos proyectos de arquitecturas ficticias y amoralidad estética no serán los códigos futuros del pensamiento revolucionario de la metrópoli digitalizada.

Lo moderno en la arquitectura es un largo camino hacia la simplificación de la forma y el espacio de la ciudad zozobra ante el hecho de enfrentarse al capitalismo preindustrial o intentar trabajar en el seno de sus diferentes contradicciones $(O$. Wagner en Viena, Tessenov en Alemania). Lo moderno como caída marca el rasgo de la pérdida de lo arquitectónico como protagonista del espacio urbano en lo social, al intentar resolver el hábitat industrial como proyectos de ejercicios mecanicistas: un utilitarismo higienista para su gleba industrial.

$\mathrm{La}$ arquitectura del siglo $\mathrm{XX}$, estuvo dirigida de manera prioritaria a liberar el espacio babitable de la miseria ambiental que la propia revolución industrial propagaba (la salubridad de las ciudades y la bigiene de la casa).

El posmodernismo ha colonizado el espacio en una fragmentación simbólica ante lo unitario del proyecto de la arquitectura, de manera que el espacio de estas arquitecturas vea truncada en parte la síntesis natural de arte y arquitectura. Resulta difícil conquistar la coberencia constructiva del objeto arquitectónico frente a los alfabetos del posmodernismo superficial del mercado de imagen. 
Comunicar, hoy, nubla, y de qué manera, el noble ejercicio de edificar y el trueque de esta «arquitectura mediada» (horrible eslogan) es hacer que la función del signo haga desaparecer la realidad, pero posibilite embellecer el espacio de su arquitectura al tiempo de su desaparición, como bien refleja la levedad del muro mientras agoniza.

La respuesta creo que no debe ser un alegato melancólico en torno a las vanguardias, como tal vez se desprenda de estos comentarios, pero sí una reflexión de saber medir los privilegios de una tecnociencia tan singular, y el efecto pragmático de seducción y delirio de las propuestas de sus escenarios e imágenes, $y$, sobre todo, no olvidar, el peligro que encierra edificar los lugares de la polis, preocupado solo por los ritos y ensueños digitalizados de las «religiones de la significación». 